\title{
Effect of extrusion of whole-grain maize flour on the characteristics of gluten-free cookies
}

\author{
Candela Paesani *, Ángela Bravo-Núñez, Manuel Gómez \\ Food Technology Area, College of Agricultural Engineering, University of Valladolid, 34071, Palencia, Spain
}

\section{A R T I C L E I N F O}

\section{Keywords:}

Gluten-free bakery products

Cookie quality

Dietary fiber

Flour extrusion

\begin{abstract}
A B S T R A C T
A gluten-free diet is usually lacking in dietary fibre and minerals present in the bran and germ of grains. The aim of this work was to study the effects of different extrusion processes of whole grain maize flours (to avoid early rancidity development of the flours) in gluten-free cookies. Particle size and hydration capacity of the flours, rheology of the doughs, physicochemical characteristics, fibre content and sensorial analysis of the cookies were evaluated. The presence of whole-grain flours increased the particle size and the water absorption values. The elastic and viscoelastic modulus of the doughs decreased, allowing a greater expansion of the cookies in the oven, resulting in cookies with a higher spread ratio (reaching values of up to 12.2) and a lower hardness (decreasing in all cases more than $25 \%$ in relation to the Control). Cookies prepared with whole grain flours presented higher values of dietary fibre $(<8.4 \mathrm{~g} / 100 \mathrm{~g}$ of lipid free cookie) and had a good acceptability. The extrusion of wholegrain maize flour has a positive impact on both in the shelf life of the flour (slower rancidity development) and in cookie quality.
\end{abstract}

\section{Introduction}

Maize, together with wheat and rice, is one of the most cultivated cereal of the world. However, the usage of maize flour in cereal-based baked products is less common than that of flours from wheat or rice. In the milling process of maize, semolina or flours can be obtained, but bran and germ are discarded. Despite of this, both bran and germ present interesting nutritional properties. Bran is rich in dietary fibre, composed of cellulose and hemicellulose, mainly arabinoxylans (Rose, Inglett, \& Liu, 2010). Arabinoxylans have demonstrated prebiotic properties (Paesani, Salvucci, Moiraghi, Fernandez Canigia, \& Pérez, 2019), accompanied by normalisation of the stool and attenuation of increases in serum cholesterol, triglyceride and glucose levels triggered by adverse dietary conditions (Broekaert et al., 2011). For its part, germ contains oils that are rich in unsaturated fatty acids and presents high contents of minerals and vitamin E (Loy \& Wright, 2003).

Different epidemiological studies have demonstrated that whole grain cereals can protect against obesity, diabetes, cardiovascular diseases or cancer (Borneo \& León, 2012). According to Fardet (2010), these effects cannot be only attributed to their fibre content, but are related to the flour structure and its derivates as well as to the antioxidant and anticarcinogenic properties of certain bioactive compounds, present in both bran and germ. Gluten-free diets usually present a deficiency in dietary fibre (DF) and micronutrients such as vitamins and minerals, which are present in bran and germ of cereals (Theethira \& Dennis, 2015; Vici, Belli, Biondi, \& Polzonetti, 2016). When maize is milled to obtain whole-grain flours, the oil present in the germ favours a fast rancidity, and bran usually generates coarser particles. Nonetheless, to improve the stability of such flour, extrusion can also be applied, reaching an adequate temperature to inactivate enzymes responsible for rancidity, reduce herbal flavours and soften the bran (Gómez, Jiménez, Ruiz, \& Oliete, 2011) and germ (Gómez, Doyagüe, \& de la Hera, 2012) of wheat. The inactivation of lipases and lipooxygenases that occurs during extrusion (Alam, Kaur, Khaira, \& Gupta, 2016) will prevent the rapid rancidity development of whole grain flours, avoiding undesirable organoleptic changes and increasing the time it takes for them to go rancid.

The usage of maize flours for the elaboration of gluten-free cookies presents promising results (Artz, Warren, Mohring, \& Villota, 1990; Mancebo, Picón, \& Gómez, 2015). Despite the nutritional interest in the use of whole grains flours in gluten-free products, there are no studies on the use of whole-grain maize. In the case of gluten-free cookies, only the use of whole-grain teff (Coleman, Abaye, Barbeau, \& Thomason, 2013) and amaranth (Calderón de la Barca, Rojas-martínez, Islas-rubio, \&

\footnotetext{
* Corresponding author.

E-mail address: candepaesani@agro.unc.edu.ar (C. Paesani).
} 
Cabrera-chávez, 2010) flour has been studied.

In this context, we investigated how extrusion treatment of wholegrain maize flour affects the quality of gluten-free sugar-snap doughs and cookies. Four flours were tested: maize control flour (only endosperm), whole-grain flour without any extrusion treatment (WG), extruded whole-grain flour (WG-S) and refined flour plus stabilized bran and germ, in the same proportions as in the whole maize kernels (WGSBG). Hydration properties of flours, rheology of the doughs, in addition to physical characteristics (dimensions, texture and colour), fibre content and acceptability of cookies were evaluated.

\section{Materials and methods}

\subsection{Materials}

All flours (extruded and non-extruded) were supplied by Dacsa Molendum (Zamora, Spain). The extrusion parameters where chosen by the company based on their own experience. The WG-S was conditioned with $10 \mathrm{~g}$ of water for $100 \mathrm{~g}$ flour at $79{ }^{\circ} \mathrm{C}$ for $35 \mathrm{~s}$. The extrusion temperature was $130{ }^{\circ} \mathrm{C}$, with a specific mechanical energy (SME) of 35 $\mathrm{W} \mathrm{h} / \mathrm{kg}$. The WG-SBG was obtained by mixing extruded bran and extruded germ with un-extruded endosperm in the same proportions as in the whole maize kernels. The bran and germ where extruded at the same time. They were conditioned with $15 \mathrm{~g}$ of water for $100 \mathrm{~g}$ flour at $82{ }^{\circ} \mathrm{C}$ for $190 \mathrm{~s}$, and extrusion was carried out at $145^{\circ} \mathrm{C}$ with an SME of $43 \mathrm{~W} \mathrm{~h} / \mathrm{kg}$. The extrusion treatments were performed with an industrial Bühler Basf singlescrew extruder (Bühler S.A., Uzil, Switzerland). The length to diameter ratio of the extruder was 20:1. The extruded product was dried by convection air until there was $10.09 \mathrm{~g} / 100 \mathrm{~g}$ moisture and then ground with a compression roller to a particle size bellow $200 \mu \mathrm{m}$.

The following ingredients were also used: margarine (Argenta crema, Puratos, Barcelona, Spain), white sugar (AB Azucarera Iberica, Valladolid, Spain) and sodium bicarbonate (Manuel Riesgo S.A., Madrid, Spain).

\subsection{Methods}

\subsubsection{Flour characterisation}

The particle size of flour was determined using a laser diffraction technique with a Malvern Mastersizer $3000 \mathrm{E}$ (Malvern Instruments Ltd., Malvern, Worcestershire, UK). The refractive index used was 1.54. The sample was automatically suspended by the equipment. The De Brouckere mean diameter (D $[4 ; 3])$ was reported. D $[4 ; 3]$ is the mean of a particle size distribution weighted by the volume. The samples were measured in duplicate.

Water-holding capacity (WHC) (method 88-04) and water-binding capacity (WBC) (method 56-30.01) were measured (AACC, 2012). All hydration properties were analysed in duplicate.

\subsubsection{Cookie making procedure}

Flour moisture was adjusted to $15 \mathrm{~g} / 100 \mathrm{~g}$. The ingredients (as g/ $100 \mathrm{~g}$ dough basis) were mixed with a Kitchen Aid 5KPM50 mixer (Kitchen Aid, Benton Harbor, Michigan, USA) using a flat beater. Briefly, preheated margarine (19.2) (1000 W for $1 \mathrm{~min}$ in microwave) was creamed with the sugar (30.8) at speed 4 for $180 \mathrm{~s}$, with intermediate scraping every $60 \mathrm{~s}$. Then, the water (6.2) was added and mixed at speed 4 for 2 min, with a scraping step at the end. Finally, maize flour (42.8) and sodium bicarbonate (0.9) were added and mixed at speed 2 for 2 min, with intermediate scraping of the surfaces of the walls of the container every $30 \mathrm{~s}$. Doughs were left to rest for $30 \mathrm{~min}$ at $25{ }^{\circ} \mathrm{C}$ wrapped in plastic, and then laminated with a Salva L-500-J sheeter (Salva, Lezo, Spain) using a gap of $6.00 \mathrm{~mm}$. The dough was then cut with circular cutter (internal diameter, $60 \mathrm{~mm}$ ) and baked in an electric oven at $185^{\circ} \mathrm{C}$ for $14 \mathrm{~min}$. At $60 \mathrm{~min}$ after baking, the resulting cookies were packed in plastic bags and stored at $25{ }^{\circ} \mathrm{C}$ until measurement. Every cookie type was elaborated in duplicate. Quality analysis (dimensions, texture and colour) was carried out with seven cookies of each batch at $24 \mathrm{~h}$ after baking.

\subsubsection{Dough rheology}

The rheological behaviour of doughs was analysed using a controlled strain rheometer (Thermo Fisher Scientific, Schwerte, Germany) equipped with a parallel-plate geometry $(60 \mathrm{~mm}$ diameter titanium serrated plate-PP60 Ti) and a water bath (Thermo Fisher Scientific, Schwerte, Germany) at $25^{\circ} \mathrm{C}$. Cookie dough pieces ( $3 \mathrm{~mm}$ height and 60 $\mathrm{mm}$ width) were placed in the rheometer, with a gap between plates of 3 mm (Freshly laminated cookie dough pieces). Vaseline oil (Panreac, Panreac Química SA, Castellar del Vallés, Spain) was applied to the exposed surfaces of the samples to prevent them drying during testing. Prior to measurements, samples were left to rest for $300 \mathrm{~s}$. First, to identify the linear viscoelastic region, a strain sweep test $(0.1-100 \mathrm{~Pa})$ at a constant frequency $(1 \mathrm{~Hz})$ was conducted. The strain value within the viscoelastic region was then used to perform a frequency sweep test $(10-0.1 \mathrm{~Hz})$. Elastic modulus $\left(\mathrm{G}^{\prime}[\mathrm{Pa}]\right)$, viscous modulus $\left(\mathrm{G}^{\prime \prime}[\mathrm{Pa}]\right)$ and loss factor $(\tan \delta$ ) were obtained. Two repetitions were performed, and each of them was analysed in duplicate.

\subsubsection{Dietary fibre in cookies}

Total dietary fibre (TDF), insoluble dietary fibre (IDF) and soluble dietary fibre (SDF) were measured using the Megazyme kit (K-TDFR200A) based on method 32-07.01 (AACC, 2012). Samples were analysed in duplicate.

\subsubsection{Cookie characteristics}

Cookie dimensions were measured with a calliper. The diameter of each cookie was measured twice, perpendicularly, to obtain an average diameter. Thickness was also measured. Then, the spread ratio of the cookies was calculated dividing the average width by the thickness.

Cookie texture was measured by a "three-point bending" test, using a TA-XT2 texture analyser (Stable Microsystems, Surrey, United Kingdom) and a sounding line HDP/3 PB with a test speed of $2.0 \mathrm{~mm} / \mathrm{s}$, following the indications of Sahagún and Gómez (2018). The maximum force needed to break the cookies (Hardness) was measured. Colour was measured using a Colorimeter PCE-CSM 1(Southampton, United Kingdom) with the D65 standard illuminant and LED light source type with blue light excitation and the $10^{\circ}$ standard observer, at the centre of the upper surface of the cookies. The results were expressed in the CIE $\mathrm{L} * \mathrm{a} * \mathrm{~b} * \mathrm{C} *$ and hue colour space. Seven cookies were measured per batch for all the analysed parameters.

\subsubsection{Consumer test}

Sensory evaluation of cookies was performed by 95 volunteers ( 42 females and 53 males), aged 18-65 years recruited at university through a sensory acceptance analysis. The cookies were coded with four-digit numbers and randomly placed on white plastic plates. Panellists were asked to evaluate appearance, odour, texture, taste and overall acceptability using a hedonic scale ranging from "I dislike very much" (1 point) to "I like very much" ( 9 points). The sensory analysis was approved by the committee of Ethics in the research of the health area of Palencia (No Register: 2019/026).

\subsubsection{Statistical analysis}

Data were studied using one-way analysis of variance (simple ANOVA). When significant ( $\mathrm{p}<0.05$ ) differences were found, Fisher's least significant differences (LSD) test was used to determine the differences among means. The Statgraphics Centurion XVIII software (StatPoint Technologies Inc, Warrenton, Virginia, USA) was used to perform the statistical analysis. 
Table 1

Maize flour and dough properties.

\begin{tabular}{cllllll}
\hline Samples & $\begin{array}{l}\text { WBC }(\mathrm{g} / \\
\mathrm{g})\end{array}$ & $\begin{array}{l}\text { WHC }(\mathrm{g} / \\
\mathrm{g})\end{array}$ & $\begin{array}{l}\mathrm{D}[4 ; \\
3]\end{array}$ & $\mathrm{G}^{\prime}\left(\mathrm{x} 10^{4}\right)$ & $\begin{array}{l}\mathrm{G}^{\prime \prime} \\
\left(\mathrm{x} 10^{4}\right)\end{array}$ & $\tan \delta$ \\
\hline Control & $1.61 \pm$ & $1.61 \pm$ & $138 \pm$ & $56.73 \pm$ & $9.71 \pm$ & $0.16 \pm$ \\
& $0.07 \mathrm{~b}$ & $0.01 \mathrm{a}$ & $6 \mathrm{a}$ & $1.63 \mathrm{c}$ & $0.98 \mathrm{c}$ & $0.03 \mathrm{a}$ \\
WG & $1.44 \pm$ & $1.77 \pm$ & $199 \pm$ & $12.83 \pm$ & $3.99 \pm$ & $0.32 \pm$ \\
& $0.06 \mathrm{a}$ & $0.03 \mathrm{~b}$ & $4 \mathrm{c}$ & $1.91 \mathrm{a}$ & $0.36 \mathrm{a}$ & $0.01 \mathrm{~d}$ \\
WG-S & $1.54 \pm$ & $1.85 \pm$ & $196 \pm$ & $18.40 \pm$ & $5.09 \pm$ & $0.28 \pm$ \\
& $0.04 \mathrm{ab}$ & $0.09 \mathrm{~b}$ & $7 \mathrm{c}$ & $1.20 \mathrm{~b}$ & $0.26 \mathrm{~b}$ & $0.01 \mathrm{c}$ \\
WG- & $2.05 \pm$ & $3.52 \pm$ & $173 \pm$ & $20.50 \pm$ & $4.89 \pm$ & $0.23 \pm$ \\
SBG & $0.04 \mathrm{c}$ & $0.05 \mathrm{c}$ & $13 \mathrm{~b}$ & $2.03 \mathrm{~b}$ & $0.33 \mathrm{~b}$ & $0.03 \mathrm{~b}$ \\
\hline
\end{tabular}

Values of particle size and hydration capacity of the flours and rheology of the cookie doughs. Whole grain (WG), Whole grain stabilized (WG-S), Whole grain with stabilized bran and germ (WG-SBG). WBC: Water binding capacity; WHC: Water Holding Capacity. The rheology values were obtained on the frequency of $1 \mathrm{HZ}$. Data are expressed as means \pm SD of the assays. Determinations were made in duplicated. The values with the same letter in the same column do not present significant differences $(\mathrm{p}<0.05)$.

\section{Results and discussion}

\subsection{Maize flour properties}

The results of WHC, WBC and particle size (D $[4 ; 3])$ of the flours are shown in Table 1 . The flour with the lowest $\mathrm{D}[4 ; 3]$ was the Control. This agrees with the findings for whole wheat flour by different authors (Bressiani et al., 2017; Wang, Khir, Pan, \& Yuan, 2017; Xiong, Zhang, Niu, \& Zhao, 2017) due to the difficulty of reducing the particle size of fibrous products such as bran. The D[4; 3] was higher for WG and WG-S flours, followed by WG-SBG. Therefore, it seems that the severe extrusion treatment makes it possible to soften the outer layers of the grain and to reduce the particle size of the bran, as noted by Wang (1993) for wheat bran.

All whole-grain samples showed higher values of WHC than the Control, most likely because of the presence of the bran rich in dietary fibre, which has been observed in other studies (Korus, Gumul, Krystyjan, Juszczak, \& Korus, 2017; Villemejane, Roussel, Berland, Aymard, \& Michon, 2013). The WG-SBG showed a significantly higher value, which may be due to the fact that the extrusion was carried out at high temperatures and with sufficient water, promoting the gelatinisation of the residual starch that remains during the process of separation of the bran and germ. According to Artz et al. (1990), the amount of residual starch contained in the bran is close to $10 \mathrm{~g} / 100 \mathrm{~g}$, and the gelatinised starch shows a high water absorption capacity (Martínez, Calviño, Rosell, \& Gómez, 2014). Water absorption may also be affected by the particle size. According to Rocha Parra, Sahagún, Ribotta, Ferrero, and Gómez (2019), higher particle sizes are related with a lower WHC capacity, probably due to the higher surface area of smaller particles (De la Hera, Talegón, Caballero, \& Gómez, 2013; Haque, Shams-Ud-Din, \& Haque, 2002). However, the effect of capillarity must also be taken into account. The WG-SBG was the flour with the smallest particle size among the whole-grain flour, which would also promote an increase in WHC. Regarding WBC values, WG was significantly lower and WG-S showed no significant differences to the Control, probably because WBC is performed in a shorter time than WHC, not allowing the bran efficient time to absorb water. The WG-SBG presented the highest value, which again may be due to the gelatinisation of starch and/or to the particle size (Abd El-Khalek \& Janssens, 2010). It is important to note that although WG-S was stabilised, the extrusion conditions of this flour prevented the gelatinisation of the starches (less humidity, time and temperature).

\subsection{Dough rheology}

Dough rheological characteristics are shown in Table 1. All samples showed a marked elastic solid-like behaviour ( $G^{\prime}$ higher than $G^{\prime \prime}$ and $\mathrm{Tg}$ delta minor than 1) throughout the frequency range (Table S1,

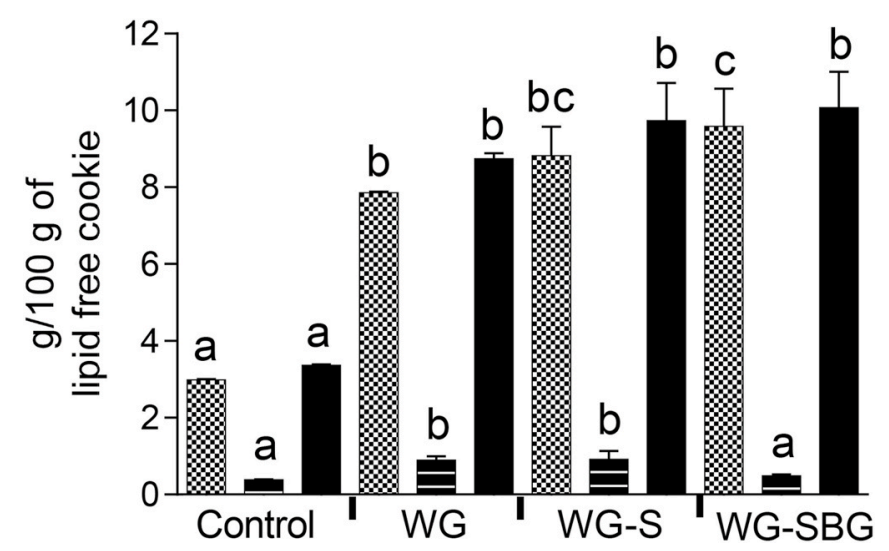

Fig. 1. Content of dietary fiber on the cookies. The black bars correspond to TDF, the striped ones to SDF and the squared ones to IDF. Whole grain (WG), Whole grain stabilized (WG-S), Whole grain with stabilized bran and germ (WG-SBG). Data are expressed as means \pm SD of the assays and express like $\mathrm{g} /$ $100 \mathrm{~g}$ of lipid free cookie. Determinations were made in duplicated. The values with the same letter in the same color bar do not present significant differences (p $<0.05)$.

supplementary material). This is in line with previous findings regarding the rheological properties of gluten-free cookie dough (Sarabhai, Sudha, \& Prabhasankar, 2017). Whole grain significantly reduced $\mathrm{G}^{\prime}$ and $\mathrm{G}^{\prime \prime}$ and increased $\mathrm{Tg}$ delta of the dough (Table 1), although other authors have reported the presence of insoluble fibre increased the rheological values in cookie doughs (Mancebo, Rodríguez, Martínez, \& Gómez, 2018). This may due to the greater $\mathrm{D}[4 ; 3]$ of bran, as opposed to that of fibres used by Mancebo et al. (2018). Belorio, Sahagún, and Gómez (2019) note that smaller values of G' correspond to flours with a higher value of D[4;3]. Finer flours have a better packing quality, which results in more cohesive doughs. Another reason for the decrease in $\mathrm{G}^{\prime}$ and $\mathrm{G}^{\prime \prime}$ in the whole doughs is based on the incorporation of maize germ, which is rich in oil (Loy \& Wright, 2003), since the incorporation of oil reduces the rheological values of the doughs (Mancebo, Martínez, Merino, de la Hera, \& Gómez, 2017). It is important to note that the doughs of the extruded flours showed higher values of G 'and G" than WG (un-extruded). Previous studies found a correlation between the rheological parameters and water absorption (Mancebo et al., 2018; Sahagún \& Gómez, 2018), which could explain the WG-SBG behaviour, as mentioned for the presence of gelatinised starch. However, WG-S flour has a WBC, WHC and a particle size similar to WG, and therefore, the differences may be due to the inactivation of certain enzymes in the thermal process, which could act by degrading the dough.

\subsection{Cookie characteristics}

\subsubsection{Dietary fibre}

The dietary fibre values of the cookies are shown in Fig. 1. Wholegrain cookies had a higher content of total dietary fibre (TDF), without significant differences among them. This increase is explained by the high fibre content of maize bran, which is mostly insoluble fibre (hemicellulose and cellulose) (Rose et al., 2010). There was a clear increase in insoluble fibre when using whole-grain flours, and only in the case of WG-SBG, there was no significant increase in soluble fibre. Our results coincide with those observed in other studies when bran from other cereals was incorporated (Sudha, Vetrimani, \& Leelavathi, 2007) or by-products of maize milling (Paraskevopoulou, Rizou, \& Kiosseoglou, 2019). The significant increase in IDF in WG-SBG could be due to the gelatinisation of starch during the extrusion process, followed by its subsequent retrogradation to form resistant starch, as was previously evaluated in another work (Vasanthan, Gaosong, Yeung, \& Li, 2002). 


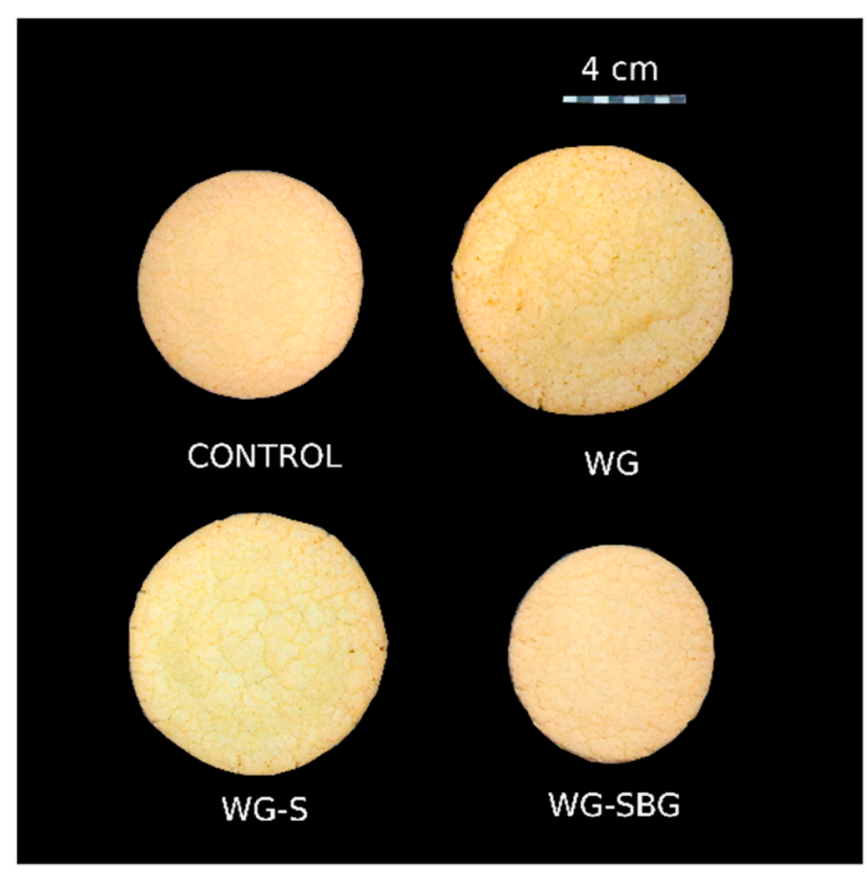

Fig. 2. Image of the cookies elaborated with the different samples. Whole grain (WG), Whole grain stabilized (WG-S), Whole grain with stabilized bran and germ (WG-SBG). A reference of $4 \mathrm{~cm}$ is placed.

Table 2

Characteristics of the elaborated cookies.

\begin{tabular}{lllll}
\hline Sample & Spread factor & $\begin{array}{l}\text { Diameter } \\
(\mathrm{mm})\end{array}$ & $\begin{array}{l}\text { Thickness } \\
(\mathrm{mm})\end{array}$ & Hardness $(\mathrm{N})$ \\
\hline Control & $7.38 \pm 0.38 \mathrm{~b}$ & $71.45 \pm 0.88 \mathrm{~b}$ & $9.74 \pm 0.54 \mathrm{c}$ & $69.47 \pm 9.71 \mathrm{~d}$ \\
WG & $12.20 \pm 1.08 \mathrm{~d}$ & $88.75 \pm 2.94 \mathrm{~d}$ & $7.32 \pm 0.61 \mathrm{a}$ & $30.71 \pm 5.49 \mathrm{a}$ \\
WG-S & $8.77 \pm 0.80 \mathrm{c}$ & $81.29 \pm 2.23 \mathrm{c}$ & $9.33 \pm 0.78 \mathrm{~b}$ & $42.97 \pm 6.17 \mathrm{~b}$ \\
WG- & $6.43 \pm 0.23 \mathrm{a}$ & $67.25 \pm 1.14 \mathrm{a}$ & $10.46 \pm 0.32 \mathrm{~d}$ & $51.00 \pm 7.45 \mathrm{c}$ \\
$\quad$ SBG & & & & \\
\hline
\end{tabular}

Physical characteristics of the cookies. Whole grain (WG), Whole grain stabilized (WG-S), Whole grain with stabilized bran and germ (WG-SBG). Data are expressed as means \pm SD of the assays. Determinations were made in duplicated. The values with the same letter in the same column do not present significant differences ( $\mathrm{p}<0.05)$.

\subsubsection{Dimensions}

Fig. 2 shows an image of the cookies, while the physical characteristics are presented in Table 2. The cookies with WG showed the highest spread factor values, followed by those with WG-S, both higher than the Control. The same was observed for cookie diameter, while for thickness, we found the opposite behaviour. In general, in studies of bran addition in cookies, the spread factor was slightly reduced or no significant differences were observed (Baumgartner, Özkaya, Saka, \& Özkaya, 2018; Sudha et al., 2007). This may be related to the fibre content, since Mancebo et al. (2018) observed a significant reduction in the spread factor when incorporating insoluble fibres, which was related to a greater capacity to absorb water. In the case of whole grain maize flours, it should be taken into account that in addition to the bran, the germ is incorporated, which is rich in oil. According to Pareyt and Delcour (2008), the higher the oil content, the greater the expansion in the oven, resulting in a higher spread factor. The larger particle size of these flours can also contribute to a higher spread factor, as shown by Belorio et al. (2019) in their study on the influence of particle size of maize flours on the quality of cookies. In contrast, WG-SBG cookies had the lowest spread factor and diameter values, even lower than the Control, and the greater thickness (Table 2). In this case, the higher values of WHC and WBC of these flours, which have been related to the
Table 3

Colour of the cookies.

\begin{tabular}{|c|c|c|c|c|c|}
\hline \multirow[t]{2}{*}{ Sample } & \multicolumn{3}{|l|}{ Colour } & \multirow[b]{2}{*}{$C^{*}$} & \multirow[b]{2}{*}{ hue } \\
\hline & $\mathrm{L}$ & $a^{*}$ & $b^{*}$ & & \\
\hline Control & $\begin{array}{l}68.40 \pm \\
1.58 \mathrm{c}\end{array}$ & $\begin{array}{l}10.45 \pm \\
0.50 \mathrm{~b}\end{array}$ & $\begin{array}{l}35.41 \pm \\
0.53 \mathrm{c}\end{array}$ & $\begin{array}{l}36.92 \pm \\
0.55 \mathrm{~b}\end{array}$ & $\begin{array}{l}0.67 \pm \\
0.01 \mathrm{~b}\end{array}$ \\
\hline WG & $\begin{array}{l}57.90 \pm \\
1.84 \mathrm{a}\end{array}$ & $\begin{array}{l}11.91 \pm \\
0.87 \mathrm{c}\end{array}$ & $\begin{array}{l}33.33 \pm \\
1.22 \mathrm{a}\end{array}$ & $\begin{array}{l}35.41 \pm \\
1.01 \mathrm{a}\end{array}$ & $\begin{array}{l}0.68 \pm \\
0.01 \mathrm{c}\end{array}$ \\
\hline WG-S & $\begin{array}{l}62.70 \pm \\
3.25 \mathrm{~b}\end{array}$ & $\begin{array}{l}9.87 \pm 0.77 \\
\mathrm{a}\end{array}$ & $\begin{array}{l}34.55 \pm \\
1.42 \mathrm{~b}\end{array}$ & $\begin{array}{l}35.93 \pm \\
1.52 \mathrm{a}\end{array}$ & $\begin{array}{l}0.67 \pm \\
0.01 \mathrm{~b}\end{array}$ \\
\hline $\begin{array}{l}\text { WG- } \\
\text { SBG }\end{array}$ & $\begin{array}{l}70.90 \pm \\
0.66 \mathrm{~d}\end{array}$ & $\begin{array}{l}10.15 \pm \\
0.38 \mathrm{ab}\end{array}$ & $\begin{array}{l}37.17 \pm \\
0.43 \mathrm{~d}\end{array}$ & $\begin{array}{l}38.53 \pm \\
0.48 c\end{array}$ & $\begin{array}{l}0.66 \pm \\
0.01 \mathrm{a}\end{array}$ \\
\hline
\end{tabular}

Whole grain (WG), Whole grain stabilized (WG-S), Whole grain with stabilized bran and germ (WG-SBG). Data are expressed as means \pm SD of the assays. Determinations were made in duplicated. The values with the same letter in the same column do not present significant differences $(\mathrm{p}<0.05)$.

spread factor in other works due to the presence of gelatinised starch and their smaller particle size compared to other whole-grain flours, may be the reason (Belorio et al., 2019; Martínez et al., 2014).

\subsubsection{Texture}

Hardness decreased in all whole-grain cookies. Other authors who incorporated bran (Baumgartner et al., 2018; Sudha et al., 2007) or insoluble fibres (Mancebo et al., 2018) have found opposite results, and cookie hardness increased. In contrast, Duta and Culetu (2015) observed a reduction in hardness when they incorporated oat bran, which they attributed to a less compact and more heterogeneous internal structure. In our case, the incorporation of the oil present in the germ also plays a role, since oil generates softer cookies (Pareyt \& Delcour, 2008). Among the whole-grain cookies, WG-SBG were hardest, which may be due to their lower spread factor. This could also be explained by the higher amount of gelatinised starch that the WG-SBG flour has due to its extrusion process, and therefore presented a higher WBC value. Correlations between both factors have been found in other articles (Belorio et al., 2019; Mancebo et al., 2018), as in this work (p < 0.01; r: 0.72). In general, our results coincide with Artz et al. (1990), who reported that the extrusion of maize bran generates cookies with greater hardness than those with the addition of untreated bran. However, these effects will depend on the extrusion conditions and the formula of the cookie.

\subsubsection{Colour}

In general, the colour of the cookies is related to the Maillard and caramelisation reactions, which take place during baking (Ameur, Mathieu, Lalanne, Trystram, \& Birlouez-Aragon, 2007). However, the colour of the flours used also has a strong influence on this parameter (Mancebo et al., 2015). The colour values of the cookies are shown in Table 3. With the exception of WG-SBG, the $L$ of the cookies decreased in the whole-grain flour, which may be related to the colour of the bran and agrees with the findings of Gujral, Mehta, Samra, and Goyal (2003) for wheat bran and Duta and Culetu (2015) for oat bran. The WG-SBG cookies were lighter in colour, which could be related to the smaller particle size, as observed by Belorio et al. (2019). In fact, WG-SBG presented the highest $C^{*}$, significantly higher than Control, and the lowest hue. The smaller particle size favours the oxidation of the compounds responsible for the yellowish and whitish colour of the flours, and therefore of the cookies. These authors also attribute this effect to the lower thickness of cookies, with high temperatures in a short time within the dough.

It is important to note that the flours that were extruded had significantly higher $\mathrm{L}, \mathrm{b} *$ and $\mathrm{C}^{*}$ values, as well as lower $\mathrm{a}^{*}$ and hue values than WG. This allows us to think that the extrusion processes affect the colour of the final products, which can have an important impact on their acceptance. The colour change of the flours is due to the temperatures reached in the extrusion process. 
Table 4

Consumer test.

\begin{tabular}{clllll}
\hline Sample & Appearance & Odour & Texture & Taste & $\begin{array}{l}\text { Overall } \\
\text { acceptability }\end{array}$ \\
\hline Control & $7.01 \pm 1.24$ & $5.94 \pm$ & $5.53 \pm$ & $5.95 \pm$ & $6.12 \pm 1.28 \mathrm{a}$ \\
& $\mathrm{c}$ & $1.59 \mathrm{a}$ & $1.56 \mathrm{a}$ & $1.61 \mathrm{a}$ & \\
WG & $5.74 \pm 1.68$ & $5.91 \pm$ & $6.15 \pm$ & $6.01 \pm$ & $6.10 \pm 1.52 \mathrm{a}$ \\
& $\mathrm{a}$ & $1.74 \mathrm{a}$ & $1.55 \mathrm{bc}$ & $1.93 \mathrm{a}$ & \\
WG-S & $6.53 \pm 1.34$ & $5.86 \pm$ & $6.00 \pm$ & $6.11 \pm$ & $6.28 \pm 1.25 \mathrm{a}$ \\
& $\mathrm{b}$ & $1.47 \mathrm{a}$ & $1.45 \mathrm{~b}$ & $1.80 \mathrm{a}$ & \\
WG- & $7.16 \pm 1.24$ & $5.74 \pm$ & $6.56 \pm$ & $6.36 \pm$ & $6.74 \pm 1.31 \mathrm{~b}$ \\
SBG & $\mathrm{c}$ & $1.62 \mathrm{a}$ & $1.82 \mathrm{c}$ & $1.72 \mathrm{a}$ & \\
\hline
\end{tabular}

Values of sensorial analysis of the cookies. Whole grain (WG), Whole grain stabilized (WG-S), Whole grain with stabilized bran and germ (WG-SBG). Data are expressed as means \pm SD of the assays. The values with the same letter in the same column do not present significant differences $(\mathrm{p}<0.05)$.

\subsubsection{Consumer test}

The results obtained in the sensory analysis are shown in Table 4. There were no significant differences between the evaluation of the odour and taste of the different cookies. In terms of appearance, the WGSBG cookie did not differ from the Control, but the other whole-grain cookies were less valued. This difference may be due to its darker colour or to excessive expansion and a rougher and less uniform surface. As for texture, all whole-grain cookies were scored better than the Control by consumers, which could be related to their lower hardness (Table 2). Finally, in terms of overall acceptability, the WG-SBG was the best-rated one, while there were no significant differences between the Control and the other whole grains cookies. It can be concluded that gluten-free whole-grain cookies provide more TDF, without a decreased quality. In addition, the extrusion treatment of WG-SBG had a positive effect on these evaluations, which can be interesting for further industrial application of this flour in cookie making. In other studies, the incorporation of cereal bran reduced the value of the cookies (Baumgartner et al., 2018; Duta \& Culetu, 2015; Sudha et al., 2007), most likely because of the incorporation of the germ, which is rich in oil and therefore compensates for the excessive dryness generated by the bran.

\section{Conclusions}

The extrusion process makes it possible to obtain whole-grain flours from which gluten-free cookies can be elaborated. These gluten-free cookies have better nutritional characteristics without reducing their acceptability. Doughs made with whole-grain flours had lower $\mathrm{G}^{\prime}$ and $\mathrm{G}^{\prime \prime}$ values and the cookies were softer, which is due to the incorporation of the germ, which is rich in oil. The effects on other parameters, such as colour or dimensions, depend on the extrusion process and its effect on starch gelatinisation. WG-S cookies presented higher spread factor and lower hardness than WG-SBG cookies, which was related with a good product quality according to sensory evaluation. The extrusion method used in WG-SBG flours masked both the characteristic colour and taste of whole grain cookies, which resulted in these cookies obtaining the best sensory. Extrusion treatments of whole maize flours could have promising application in the gluten-free industry.

\section{CRediT authorship contribution statement}

Candela Paesani: Methodology, Validation, Formal analysis, Investigation, Writing - original draft, Visualization. Ángela BravoNúñez: Methodology, Validation, Writing - review \& editing. Manuel Gómez: Conceptualization, Methodology, Writing - review \& editing, Supervision, Project administration, Funding acquisition.

\section{Declaration of competing interest}

The authors declare that they have no known competing financial interests or personal relationships that could have appeared to influence the work reported in this paper.

\section{Acknowledgements}

The authors are grateful to FEDER-Interreg España-Portugal programme for financial support through the project TRANSCoLAB 0612_TRANS_CO_LAB_2_P. Ángela Bravo-Núñez would like to acknowledge the University of Valladolid for her postdoctoral contract. The authors are also grateful to Dacsa Molendum (Zamora, Spain) for supplying the raw materials.

\section{Appendix A. Supplementary data}

Supplementary data to this article can be found online at https://doi. org/10.1016/j.lwt.2020.109931.

\section{References}

AACC. (2012). Approved methods of the American association of cereal chemists. Method 1091 (11th ed.). St. Paul, Minnesota: American Association of Cereal Chemists.

Abd El-Khalek, E., \& Janssens, G. P. J. (2010). Effect of extrusion processing on starch gelatinisation and performance in poultry. World's Poultry Science Journal, 66(1), 53-63. https://doi.org/10.1017/S0043933910000073.

Alam, M. S., Kaur, J., Khaira, H., \& Gupta, K. (2016). Extrusion and extruded products: Changes in quality attributes as affected by extrusion process parameters: A review. Critical Reviews in Food Science and Nutrition, 56(3), 445-473. https://doi.org/ 10.1080/10408398.2013.779568.

Ameur, L. A., Mathieu, O., Lalanne, V., Trystram, G., \& Birlouez-Aragon, I. (2007). Comparison of the effects of sucrose and hexose on furfural formation and browning in cookies baked at different temperatures. Food Chemistry, 101(4), 1407-1416. https://doi.org/10.1016/j.foodchem.2006.03.049.

Artz, W., Warren, C., Mohring, A., \& Villota, R. (1990). Incorporation of corn fiber into sugar snap cookies. Cereal Chemistry, 67(3), 303-305.

Baumgartner, B., Özkaya, B., Saka, I., \& Özkaya, H. (2018). Functional and physical properties of cookies enriched with dephytinized oat bran. Journal of Cereal Science, 80, 24-30. https://doi.org/10.1016/j.jcs.2018.01.011.

Belorio, M., Sahagún, M., \& Gómez, M. (2019). Influence of flour particle size distribution on the quality of maize gluten-free cookies. Foods, 8(2). https://doi.org/ $10.3390 /$ foods 8020083 .

Borneo, R., \& León, A. E. (2012). Whole grain cereals: Functional components and health benefits. Food and Function, 3(2), 110-119. https://doi.org/10.1039/c1fo10165j.

Bressiani, J., Oro, T., Santetti, G. S., Almeida, J. L., Bertolin, T. E., Gómez, M., et al. (2017). Properties of whole grain wheat flour and performance in bakery products as a function of particle size. Journal of Cereal Science, 75, 269-277. https://doi.org/ 10.1016/j.jcs.2017.05.001.

Broekaert, W. F., Courtin, C. M., Verbeke, K., van de Wiele, T., Verstraete, W., \& Delcour, J. A. (2011). Prebiotic and other health-related effects of cereal-derived arabinoxylans, arabinoxylan-oligosaccharides, and xylooligosaccharides. Critical Reviews in Food Science and Nutrition, 51(2), 178-194. https://doi.org/10.1080/ 10408390903044768.

Calderón de la Barca, A. M., Rojas-martínez, M. E., Islas-rubio, A. R., \& Cabrerachávez, F. (2010). Gluten-free breads and cookies of raw and popped amaranth flours with attractive technological and nutritional qualities. https://doi.org/10.1007/s11130010-0187-z.

Coleman, J., Abaye, A. O., Barbeau, W., \& Thomason, W. (2013). The suitability of teff flour in bread, layer cakes. Cookies and Biscuits, 7486, 1-5. https://doi.org/10.3109/ 09637486.2013.800845.

De la Hera, E., Talegón, M., Caballero, P., \& Gómez, M. (2013). Influence of maize flour particle size on gluten-free breadmaking. Journal of the Science of Food and Agriculture, 93(4), 924-932. https://doi.org/10.1002/jsfa.5826.

Duta, D. E., \& Culetu, A. (2015). Evaluation of rheological, physicochemical, thermal, mechanical and sensory properties of oat-based gluten free cookies. Journal of Food Engineering, 162, 1-8. https://doi.org/10.1016/j.jfoodeng.2015.04.002.

Fardet, A. (2010). New hypotheses for the health-protective mechanisms of whole-grain cereals: What is beyond fibre? Nutrition Research Reviews, 23(1), 65-134. https://doi. org/10.1017/S0954422410000041.

Gómez, M., Doyagüe, M. J., \& de la Hera, E. (2012). Addition of pin-milled pea flour and air-classified fractions in layer and sponge cakes. Lebensmittel-Wissenschaft und -Technologie- Food Science and Technology, 46(1), 142-147. https://doi.org/10.1016/ j.lwt.2011.10.014.

Gómez, M., Jiménez, S., Ruiz, E., \& Oliete, B. (2011). Effect of extruded wheat bran on dough rheology and bread quality. Lebensmittel-Wissenschaft und -Technologie- Food Science and Technology, 44(10), 2231-2237. https://doi.org/10.1016/j. lwt.2011.06.006.

Gujral, H. S., Mehta, S., Samra, I. S., \& Goyal, P. (2003). Effect of wheat bran, coarse wheat flour, and rice flour on the instrumental texture of cookies. International Journal of Food Properties, 6(2), 329-340. https://doi.org/10.1081/JFP-120017816. 
Haque, M. A., Shams-Ud-Din, M., \& Haque, A. (2002). The effect of aqueous extracted wheat bran on the baking quality of biscuit. International Journal of Food Science and Technology, 37(4), 453-462. https://doi.org/10.1046/j.1365-2621.2002.00583.x.

Korus, A., Gumul, D., Krystyjan, M., Juszczak, L., \& Korus, J. (2017). Evaluation of the quality, nutritional value and antioxidant activity of gluten-free biscuits made from corn-acorn flour or corn-hemp flour composites. European Food Research and Technology, 243(8), 1429-1438. https://doi.org/10.1007/s00217-017-2853-y.

Loy, D. D., \& Wright, K. N. (2003). Nutritional properties and feeding value of corn and its by- products. In P. J. White, \& L. A. Johnson (Eds.), Corn. chemistry and technology (pp. 571-604). St Paul. Minnesota: American Association of Cereal Chemist.

Mancebo, C. M., Martínez, M. M., Merino, C., de la Hera, E., \& Gómez, M. (2017). Effect of oil and shortening in rice bread quality: Relationship between dough rheology and quality characteristics. Journal of Texture Studies, 48(6), 597-606. https://doi.org/ 10.1111/jtxs.12270.

Mancebo, C. M., Picón, J., \& Gómez, M. (2015). Effect of flour properties on the quality characteristics of gluten free sugar-snap cookies. Lebensmittel-Wissenschaft und -Technologie- Food Science and Technology, 64(1), 264-269. https://doi.org/10.1016/ j.lwt.2015.05.057.

Mancebo, C. M., Rodríguez, P., Martínez, M. M., \& Gómez, M. (2018). Effect of the addition of soluble (nutriose, inulin and polydextrose) and insoluble (bamboo, potato and pea) fibres on the quality of sugar-snap cookies. International Journal of Food Science and Technology, 53(1), 129-136. https://doi.org/10.1111/ijfs.13566.

Martínez, M. M., Calviño, A., Rosell, C. M., \& Gómez, M. (2014). Effect of different extrusion treatments and particle size distribution on the physicochemical properties of rice flour. Food and Bioprocess Technology, 7(9), 2657-2665. https://doi.org/ 10.1007/s11947-014-1252-7.

Paesani, C., Salvucci, E., Moiraghi, M., Fernandez Canigia, L., \& Pérez, G. T. (2019). Arabinoxylan from Argentinian whole wheat flour promote the growth of Lactobacillus reuteri and Bifidobacterium breve. Letters in Applied Microbiology, 68 (2), 142-148. https://doi.org/10.1111/lam.13097.

Paraskevopoulou, A., Rizou, T., \& Kiosseoglou, V. (2019). Biscuits enriched with dietary fibre Powder obtained from the water-Extraction Residue of maize milling byproduct. Plant Foods for Human Nutrition, 74(3), 391-398. https://doi.org/10.1007/ s11130-019-00752-8.

Pareyt, B., \& Delcour, J. A. (2008). The role of wheat flour constituents, sugar, and fat in low moisture cereal based products: A review on sugar-snap cookies. Critical Reviews in Food Science and Nutrition, 48(9), 824-839. https://doi.org/10.1080/ 10408390701719223.

Rocha Parra, A. F., Sahagún, M., Ribotta, P. D., Ferrero, C., \& Gómez, M. (2019). Particle size and hydration properties of dried apple pomace: Effect on dough viscoelasticity and quality of sugar-snap cookies. Food and Bioprocess Technology, 12(7), 1083-1092. https://doi.org/10.1007/s11947-019-02273-3.

Rose, D. J., Inglett, G. E., \& Liu, S. X. (2010). Utilisation of corn (Zea mays) bran and corn fiber in the production of food components. Journal of the Science of Food and Agriculture, 90(6), 915-924. https://doi.org/10.1002/jsfa.3915.

Sahagún, M., \& Gómez, M. (2018). Influence of protein source on characteristics and quality of gluten-free cookies. Journal of Food Science \& Technology, 94, 50-56. https://doi.org/10.1007/s13197-018-3339-z.

Sarabhai, S., Sudha, M. L., \& Prabhasankar, P. (2017). Rheological characterization and biscuit making potential of gluten free flours. Journal of Food Measurement and Characterization, 11(3), 1449-1461. https://doi.org/10.1007/s11694-017-9524-3.

Sudha, M. L., Vetrimani, R., \& Leelavathi, K. (2007). Influence of fibre from different cereals on the rheological characteristics of wheat flour dough and on biscuit quality. Food Chemistry, 100(4), 1365-1370. https://doi.org/10.1016/j. foodchem.2005.12.013.

Theethira, T. G., \& Dennis, M. (2015). Celiac disease and the gluten-free diet: Consequences and recommendations for improvement. Digestive Diseases, 33(2), 175-182. https://doi.org/10.1159/000369504.

Vasanthan, T., Gaosong, J., Yeung, J., \& Li, J. (2002). Dietary fiber profile of barley flour as affected by extrusion cooking. Food Chemistry, 77(1), 35-40. https://doi.org/ 10.1016/S0308-8146(01)00318-1.

Vici, G., Belli, L., Biondi, M., \& Polzonetti, V. (2016). Gluten free diet and nutrient deficiencies: A review. Clinical Nutrition, 35(6), 1236-1241. https://doi.org/ 10.1016/j.clnu.2016.05.002.

Villemejane, C., Roussel, P., Berland, S., Aymard, P., \& Michon, C. (2013). Technological and sensory tools to characterize the consistency and performance of fibre-enriched biscuit doughs. Journal of Cereal Science, 57(3), 551-559. https://doi.org/10.1016/j. jcs.2013.03.005.

Wang, W. M., C, K., \& J, P. (1993). Effects of twinn-screw extrusion on the physical properties of dietary fiber and other components of whole wheat and wheat bran and on the baking quality of the wheat bran. American Association of Cereal Chemists, 70 (6), 707-711.

Wang, T., Khir, R., Pan, Z., \& Yuan, Q. (2017). Simultaneous rough rice drying and rice bran stabilization using infrared radiation heating. Lebensmittel-Wissenschaft und -Technologie- Food Science and Technology, 78, 281-288. https://doi.org/10.1016/j. lwt.2016.12.041.

Xiong, L., Zhang, B., Niu, M., \& Zhao, S. (2017). Protein polymerization and water mobility in whole-wheat dough influenced by bran particle size distribution. Lebensmittel-Wissenschaft und -Technologie-Food Science and Technology, 82, 396-403. https://doi.org/10.1016/j.lwt.2017.04.064. 